\title{
ESTIMATIVA DE VIDA ÚTIL EM EDIFICAÇÃO EM ESTRUTURA DE CONCRETO ARMADO EM AMBIENTE MARINHO E URBANO
}

\author{
GUIGNONE, GUILHERME \\ MSc. Arquiteto \\ Universidade Federal do Espírito Santo (UFES) \\ Espírito Santo; Brasil \\ guilhermecguignone@gmail.com
}

\section{BAPTISTA, GERCYR}

MSc. Engenheiro Civil

Universidade Federal do Espírito Santo (UFES)

Espírito Santo; Brasil

gercyr@gmail.com

\author{
VIEIRA, GEILMA \\ Prof. DSc. Engenheira Civil \\ Universidade Federal do Espírito Santo (UFES) \\ Espírito Santo; Brasil \\ geilma.vieira@gmail.com
}

\section{RESUMO}

Este artigo objetiva investigar a vida útil de projeto (VUP) de edificação em estrutura de concreto armado construída em ambiente marinho e urbano cuja obra não foi concluída. A edificação encontra-se com a superestrutura dos pavimentos superiores exposta ao meio por um período de vinte e cinco anos, tornando-se relevante verificar o seu estado de conservação. Foram realizados ensaios de esclerometria, de detecção eletromagnética da armadura, de velocidade de propagação de onda e de indicadores colorimétricos. A partir dos resultados, pôde-se estimar a vida útil de Projeto (VUP) da estrutura e comparar com o estágio VUP atual. Realizou-se também a previsão de vida útil por meio das ferramentas computacionais 365 Life e Carambola. A partir dos resultados, contatou-se que a edificação apresenta resposta satisfatória em relação à estimativa de vida útil, pontuando resultados equivalentes entre o estimado e o aferido com relação à frente de carbonatação e superiores no que tange ao avanço de cloretos.

Palavras-chave: durabilidade, vida útil, íons cloreto, carbonatação, simuladores computacionais.

\section{ABSTRACT}

This article aims to investigate the service life of the building in the reinforced concrete structure built in the marine and urban environment whose construction has not been completed. The building meets the superstructure of the upper floors exposed to the environment for a period of twenty-five years, making it relevant to verify its state of conservation. Were performed sclerometry tests, electromagnetic reinforcement detection tests, ultrasonic wave propagation velocity tests and colorimetric indicator tests. From the results, it was possible to estimate the service life of the structure and compare it with the current service life stage. For comparative purposes, life expectancy was also performed using the computational tools 365 Life and Carambola. It was verified, from the results, that the building in its present state presents a satisfactory answer in relation to the estimated service life, punctuating equivalent results between the estimated and the measured with respect to the carbonation front and superiors regarding the advancement of chlorides.

Keywords: durability, service life, chloride ions, carbonation, computer simulators.

\section{INTRODUÇÃ̃o}

O concreto armado é um dos materiais mais utilizados no mundo e com certeza um dos mais estudados. Pesquisas diversas se orientam em potencializar a eficiência deste material, principalmente com relação às suas propriedades mecânicas e aquelas relacionadas com a durabilidade (THOMAS, BAMFORTH, 1999; KAMALI, GHAHREMANINEZHAD, 2015; GLEIZE, ESCADEILLAS, 2007). No que se refere à durabilidade, estudos demonstram a eficiência da utilização de tecnologias como: incorporação de materiais cimeticios, pozolanas de alta reatividade, aditivos químicos, dentre outras soluções. Entretanto, as iniciativas mais eficientes ainda são a adoção de medidas e diretrizes pautadas em normas técnicas desde a fase de concepção do empreendimento até a fase de execução, além do uso adequado dessas estruturas.

Helene (2001) apresenta diretriz conhecida como Regra dos 4c composta por: composição do traço do concreto; compactação ou adensamento efetivo do concreto na estrutura; cura efetiva do concreto na estrutura e cobrimento ou 
espessura do concreto de cobrimento das armaduras. $\mathrm{O}$ atendimento a estes parâmetros configura-se premissa para que as estruturas atendam ou superem a expectativa de vida útil a que foram concebidas.

Segundo o American Concrete Institute (ACI 201, 1992) a durabilidade do concreto é definida como a capacidade deste resistir à ação de intempéries, ataques químicos, abrasão ou qualquer outro processo de deterioração. A NBR ABNT 6118 (2014), para projeto de estruturas de concreto, determina que as estruturas de concreto devem ser projetadas e construídas sob condições ambientais preconizadas em projeto, conservando sua segurança, estabilidade e aptidão de serviço durante o período correspondente a sua vida útil. Conforme Isaia (2001), a durabilidade está relacionada com a sua capacidade de se conservar em determinado estado, com a mesma qualidade, ao longo de um dado tempo ou ainda é a resistência de um material ou elemento de construção à deterioração ou degradação.

Os mecanismos de deterioração do concreto e o surgimento de manifestações patológicas referem-se, dentre outros, à resposta do material ao meio no qual está inserido. Nesse caso, a resistência à penetração de agentes agressivos no interior do concerto é fator relevante. Os principais agentes de deterioração são o $\mathrm{CO}_{2}$ e os íons cloretos e quanto maior a porosidade do material maior a facilidade de ingresso (CASCUDO, 1997; HELENE, 1993; SOUSA e RIPPER, 1998; RIBEIRO et. al, 2014). O ingresso de $\mathrm{CO}_{2}$ no concreto pode causar a manifestação patológica conhecida como carbonatação. Conforme Pauletti (2009), a carbonatação se configura por ser um fenômeno físico-químico que ocorre principalmente entre os compostos hidratados do cimento, especialmente hidróxido de cálcio, e o $\mathrm{CO}_{2}$ da atmosfera, reduzindo a alcalinidade do concreto. Esta redução da alcalinidade pode se tornar crítica para a corrosão da armadura.

Os íons cloretos do ambiente podem ingressar na estrutura do concreto através dos mecanismos de penetração de água contaminada e de difusão de íons. Para que ocorra a contaminação, os íons precisam estar dissolvidos em água. Como cristal sólido, o cloreto não oferece risco elevado para as estruturas, pois não penetra nos poros. Apesar disso, no estado sólido, o íon pode se depositar por impactação na superfície do concreto e permanecer até que até que uma chuva o dissolva e o transporte para o interior da estrutura através de absorção capilar ou difusão (HELENE, 1993; MEDEIROS, 1993). A literatura aponta a corrosão da armadura devido à ação dos íons cloretos como um dos problemas mais sérios que podem ocorrer nas estruturas de concreto (ANDRADE, 1997, NEVILLE, 1997)

Segundo Neville (1997) o que determina o mecanismo de transporte dominante no concreto é a configuração dos poros (tipo e distribuição do tamanho dos poros ou microfissuras) e a porcentagem preenchida com água. Além disso, os fatores ligados à dosagem e à execução, relação água/aglomerante, tipo de cimento, adições, condições de cura, relacionam-se com a dificuldade ou a facilidade dos agentes agressivos penetrarem no concreto.

A avaliação da Vida Útil de Projeto (VUP) de estruturas de concreto corresponde ao período de tempo em que a frente de cloretos ou a frente de carbonatação atinja a armadura em condições capazes de despassívá-la (HELENE, 1993). Há diversos modelos para sua previsão como: com base em experiências anteriores, com o auxílio de ensaios acelerados, com enfoque determinista (leis de Fick em ensaios de migração de cloretos) e com métodos probabilísticos (HELENE, 2004). Pesquisas indicam que é possível estimar a Vida Útil de Projeto (período de iniciação) por meio do coeficiente de difusão de cloretos obtido por ensaios acelerados de migração de cloretos e indicadores colorimétricos (LUPING, 1992). Com relação à estimativa de Vida Útil de Projeto (VUP) por meio da frente de carbonatação, podem ser usados coeficientes relacionados ao tipo de cimento, condições ambientais, teor de ar introduzido no concreto dentre outros (HAKKINEN, 1993). É possível também obter resultados de vida útil por meio de simuladores computacionais. A análise entre os diferentes métodos de investigação disponíveis, quer seja considerando a estimativa de projeto, quer seja utilizando-se de parâmetros obtidos em ensaios executados em estrutura real, considerando o estado real de conservação da edificação, merece avaliação.

Este trabalho avaliou o estado de deterioração e a vida útil de edificação em estrutura de concreto armado com idade em torno de vinte e cinco anos e exposta aos principais agentes agressivos do meio marinho e urbano - incidência de $\mathrm{CO}_{2} \mathrm{e}$ de íons cloreto. Uma análise comparativa considerando estimativas de vida útil de projeto e o estágio atual de deterioração foi abordada. Auxilio de ferramentas computacionais também foram adotadas a fim de confrontar com os resultados obtidos. Pôde-se constatar que cuidados relativos à correta concepção de traços, adoção de materiais adequados e execução em acordo com as normas técnicas, proporcionam caminho favorável ao cumprimento da expectativa de vida útil projetada, neste contexto a edificação objeto de estudo torna-se referencial.

\section{EXPERIMENTO}

\subsection{Objeto de avaliação}

A análise refere-se a uma edificação localizada no município de Cariacica (ES) (temperatura média de $24.5^{\circ} \mathrm{C}$ e pluviosidade média anual de $1143 \mathrm{~mm}$ ) com início de execução no fim dos anos 1980 e abandonada no início dos anos 2000. Em 2006, a edificação, após ser desapropriada, foi doada pelo Governo do Estado do Espírito Santo ao Instituto Federal do Espírito Santo - IFES para utilização das instalações do Campus Cariacica, região de Grande Vitória. Em 2010 iniciou-se a primeira etapa de construção do IFES, contemplando o pavimento térreo e o primeiro pavimento. A 
estrutura da edificação, pertinente aos pavimentos superiores, encontra-se atualmente sem uso, desabrigada e exposta a agentes agressivos (aproximadamente 25 anos, sem que tenham sido efetivadas medidas preventivas e corretivas de proteção e reparo). Mediante este quadro, torna-se relevante verificar o atual estágio de degradação desta estrutura para fins de utilização do prédio em sua plenitude. A Figura 1 apresenta a sua localização e a proximidade em relação ao mar.

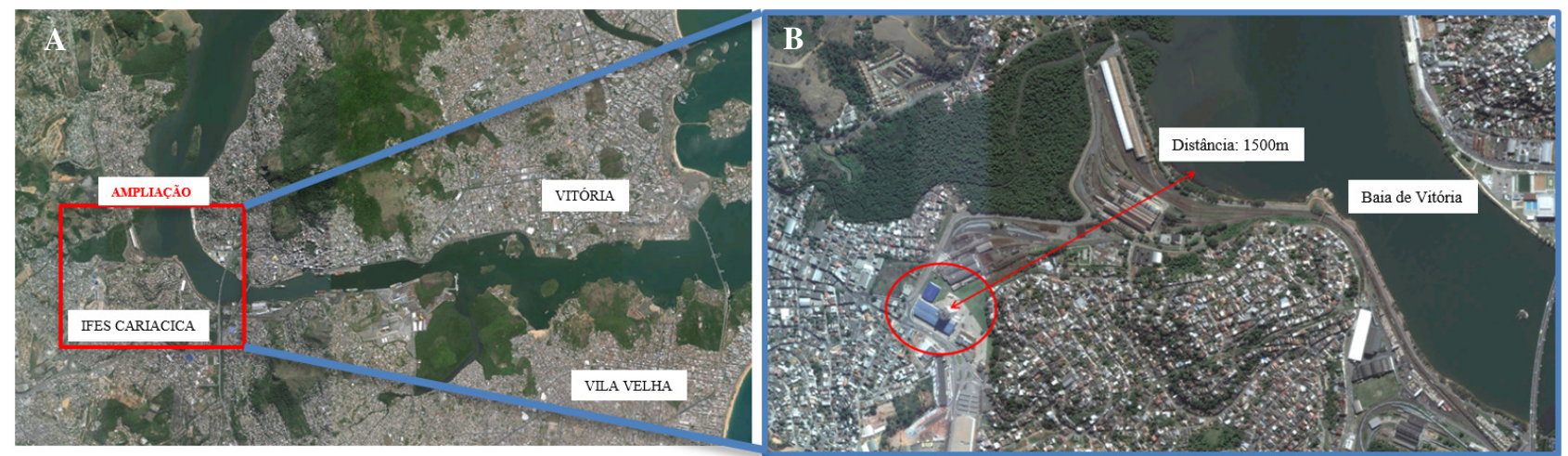

Figura 1: (a) localização da edificação, (b) ampliação: distância em relação ao mar; Fonte: Google Earth

Além da depredação da obra após a paralisação das atividades, a edificação teve sua estrutura exposta a intempéries, ambiente úmido, temperaturas elevadas, incidência de névoa salina (devido à proximidade com o mar aproximadamente 1500 metros), dentre outros aspectos. Conforme Figura 2, a edificação contempla sua parte inferior reformada e utilizada para o IFES e a parte superior, sem utilização e com sua estrutura exposta ao meio.
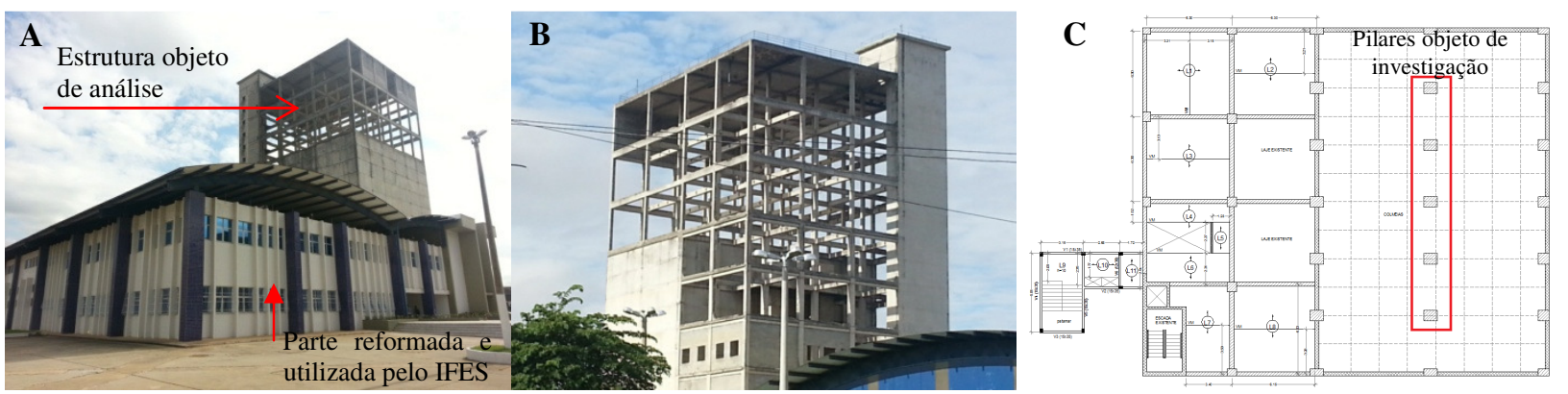

Figura 2: (a) empreendimento vista geral, (b) objeto de avaliação e (c) planta baixa

\subsection{Métodos}

Após a inspeção visual da edificação, tornou-se necessária a execução de ensaios a fim de melhor detectar o seu estado de conservação. Como premissa, adotaram-se ensaios não destrutivos, que menos impactassem na estrutura.

\subsubsection{Detecção eletromagnética da armadura}

O ensaio de detecção eletromagnética da armadura, também denominado de pacometria, (British Standard BS1881: Part 204) é utilizado para avaliar, por meio de correntes eletromagnéticas, a posição, o diâmetro e o cobrimento da armadura. Primeiramente, localiza-se a posição da armadura na estrutura, para proceder-se à abertura do concreto evitando danos exagerados à estrutura durante a inspeção. Em um segundo momento, pode-se averiguar o valor do cobrimento e o diâmetro da armadura. De acordo com Santos (2008), o ensaio baseia-se na leitura da interação entre uma frequência baixa de um campo eletromagnético criado pelo equipamento e a armação detectada. A partir dos dados recolhidos, intensidade e frequência, é possível estimar o diâmetro e o cobrimento das armaduras.

\subsubsection{Determinação da velocidade de propagação de onda ultrassônica}

Outro importante ensaio recomendado é o de determinação da velocidade de propagação de onda ultrassônica (ABNT NBR 8802:2013), que revela o tempo que o transmissor do equipamento chega ao receptor. Assim, verifica-se a compacidade do material - conhecendo a condição de porosidade do elemento; fator determinante para o avanço de cloretos até a armadura - e outras situações como bicheiras, vazios, elementos ocultos no interior da peça estrutural e até mesmo água aprisionada. Torna-se possível também correlacionar a velocidade de transmissão com a resistência do 
concreto. Conforme NM 58 (1996), as principais aplicações do ultrassom são as seguintes: determinação da uniformidade do concreto; detecção da presença de vazios, fissuras e outras imperfeições; estimativa da resistência à compressão do concreto; determinação do módulo de elasticidade dinâmico e coeficiente de Poisson. Por meio da Tabela 1 apresenta-se uma interpretação possível da qualidade do concreto em função da velocidade de propagação da onda sonora em seu interior, de acordo com a norma utilizada na aplicação dessa técnica (BS EN12504-4/2004).

Tabela 1 - Relação entre a velocidade de propagação e a qualidade do concreto

\begin{tabular}{c|c}
\hline Velocidade longitudinal da onda em $(\mathrm{Km} / \mathrm{s})$ & Qualidade do concreto \\
\hline $\mathrm{v}<2$ & Muito fraca \\
\hline $2<\mathrm{v}<3$ & Fraca \\
\hline $3<\mathrm{v}<3,5$ & Média \\
\hline $3,5<\mathrm{v}<4$ & Boa \\
\hline $4<\mathrm{v}<4,5$ & Muito boa \\
\hline $4,5>\mathrm{v}$ & Excelente \\
\hline
\end{tabular}

Fonte: Ribeiro et. al, 2014

\subsubsection{Ensaio de indicador colorimétrico de aspersão de fenolftaleína}

Os ensaios contemplando medidas de indicadores colorimétricos informam se a armadura está em zona carbonatada (por meio do uso de fenolftaleína) ou se está exposta ao avanço de cloretos e ainda se os íons cloretos alcançaram a armadura em condições críticas capazes de despassivá-la (uso de nitrato de prata). O ensaio de profundidade de carbonatação permite avaliar o avanço da carbonatação do concreto. A carbonatação do concreto, devido à ação do $\mathrm{CO}_{2}$ atmosférico, leva à redução da sua alcalinidade e, consequentemente, à corrosão das armaduras (HELENE, 1993). Com a carbonatação, há a redução do $\mathrm{pH}$ inicial do concreto (pH entre 12 a 14) provocada pela reação do $\mathrm{CO}_{2}$ do meio com os álcalis do cimento (hidróxidos de cálcio, sódio e potássio), formando carbonatos e diminuindo o $\mathrm{pH}$ do concreto. Utiliza-se como sistema indicador a fenolftaleína que apresenta coloração róseo-avermelhada com valores de pH iguais ou superiores a 9.5 e incolor abaixo desse valor. Em geral, aplica-se uma solução de $1 \mathrm{~g}$ de fenolftaleína dissolvida em $50 \mathrm{~g}$ de álcool e $50 \mathrm{~g}$ de água, que é borrifada na superficie de fratura. Inicialmente, faz-se uma abertura no concreto até expor a armadura, aplica-se em forma de spray a solução de fenolftaleína e faz a leitura da profundidade de carbonatação (medida da zona incolor), a partir da superficie do concreto (RIBEIRO et. al, 2014; CASCUDO, 1997).

\subsubsection{Ensaio de indicador colorimétrico de aspersão de nitrato de prata}

Ainda no que se referem aos ensaios por indicadores colorimétricos, o ensaio de aspersão de nitrato de prata visa identificar a camada contaminada por cloretos livres. Promove-se a abertura localizada da camada de concreto sobre a armadura e aplica-se a solução. A camada onde não há a presença de cloretos livres apresenta coloração marrom e a camada onde há presença apresenta-se esbranquiçada.

\subsection{Procedimentos de investigação}

\subsubsection{Realizações ensaios "in-loco"}

Efetuaram-se ensaios nos pilares centrais da edificação em decorrência da maior facilidade de execução de ensaios de velocidade de propagação ultrassônica por mecanismo direto e por apresentarem, na inspeção visual e nas análises de esclerometria, similaridade com os demais elementos estruturais. Dentre os elementos estruturais, os pilares foram adotados por configurarem elementos esbeltos e por apresentarem faces mais expostas aos agentes agressivos em detrimento das lajes, por exemplo. Os pilares avaliados encontravam-se no pavimento térreo, local de acesso viável. Inicialmente, foi realizada a detecção eletromagnética da armadura a fim do reconhecimento da armadura executada, visando viabilizar os ensaios realizados na sequência. A Figura 3 apresenta o ensaio de detecção eletromagnética da armadura sendo executado. A partir do reconhecimento da posição da armadura, tornou-se possível realizar o ensaio de velocidade de propagação de onda ultrassônica (VPOU). Adotou-se como premissa realizar medições em regiões mais afastadas possíveis das barras visando investigar a qualidade do concreto sem interferência com a armadura. A presença das armaduras no concreto podem proporcionar distorções nos resultados do ensaio de ultrassom. De acordo com o relatório ACI 228.1R-03 (2003), a quantidade e a posição da armadura no concreto exerce influência na velocidade de propagação do pulso ultrassônico (VPOU), pois a velocidade é aproximadamente 40\% maior do que no concreto, principalmente quando as barras são orientadas paralelamente à direção de propagação do pulso. Segundo Naik et al. (2004), no concreto armado a velocidade do pulso próxima das armaduras é superior àquela do concreto simples de 
mesma composição, atingindo um valor em torno de $40 \%$ a $70 \%$ maior, chegando à ordem de $5900 \mathrm{~m} / \mathrm{s}$ no aço, para um meio sólido e infinito. Medeiros (2007), afirma que barras de aço paralelas à direção das leituras com o ultrassom pelo modo de transmissão indireto podem influenciar nos resultados dos ensaios de VPOU.

Após a execução dos ensaios de VPOU efetuaram-se os ensaios de indicadores colorimétricos e, para efeito, foi executada a retirada do cobrimento da armadura e a aspersão de fenolftaleína e nitrato de prata (Figura 4b). Após a exposição da armadura, tornou-se possível verificar o cobrimento utilizado no pilar de 40mm, conforme preconiza a ABNT NBR 6118:2014 para a classe de agressividade em que está situada a edificação, classe de agressividade forte, classificação marinha e com risco grande de deterioração da estrutura. Revelou-se ainda que o resultado identificado no ensaio de detecção eletromagnética da armadura encontrava-se de acordo com o projetado. Em seguida, iniciaram-se os ensaios de indicadores colorimétricos e para efeito foi individualizada a região a ser analisada em duas, análise de área carbonatada, utilizando-se aspersão de fenoftaleina e análise de área com cloretos livres, aspersão de nitrato de prata (Figura 4c).
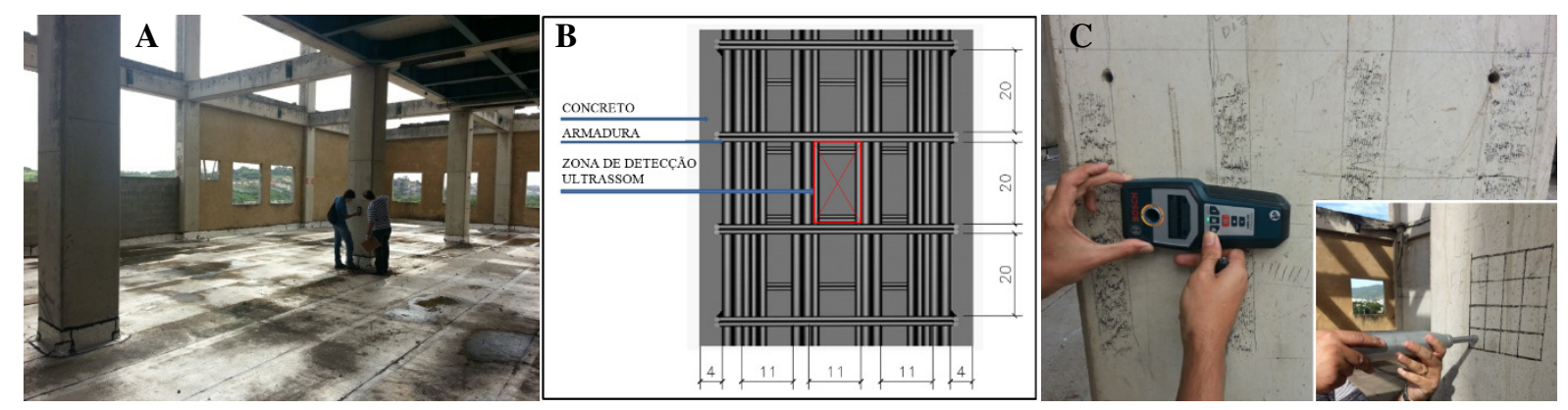

Figura 3: (a) ensaios em execução, (b) representação da posição das barras e (c) detecção eletromagnética e esclerometria
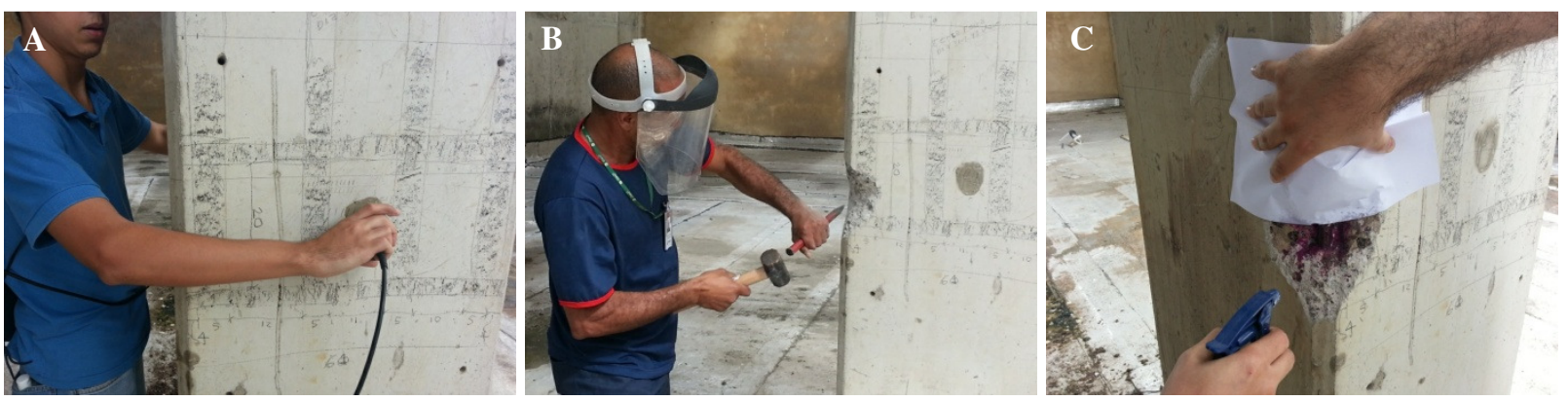

Figura 4: (a) ensaio de VPOU, (b) retirada do cobrimento e (c) indicador colorimétrico

\subsubsection{Procedimento de avaliação de vida útil}

Por intermédio dos resultados de frente de penetração de cloretos e de frente de carbonatação, efetuou-se a estimativa de vida útil. No que se refere à avaliação por cloretos, a análise depende do reconhecimento da resistência à compressão do concreto a fim de investigar, de modo aproximado, a mistura adotada na execução dos pilares. Conforme British Standards Institution (1986) é possível usar relações empíricas para estimar os valores de módulo de elasticidade estático e dinâmico por meio de velocidade de propagação de ondas ultrassônicas realizadas em qualquer ponto da estrutura. Estas relações são dadas na Tabela 2 para aplicação aos concretos executados com os tipos mais comuns de agregado natural. A estimativa do módulo de elasticidade estático e dinâmico obtido a partir desta tabela terá uma precisão melhor que $10 \%$.

Tabela 2 - Correlação empírica entre módulo de elasticidade estático e dinâmico e velocidade de propagação de onda

\begin{tabular}{c|c|c}
\hline \multirow{2}{*}{ Velocidade ultra-sônica $(\mathrm{Km} / \mathrm{s})$} & \multicolumn{2}{|c}{ Módulo de elasticidade $\left(\mathrm{MN} / \mathrm{m}^{2}\right)$} \\
\cline { 2 - 3 } & Dinâmico & Estático \\
\hline 3,6 & 24.000 & 13.000 \\
\hline 3,8 & 26.000 & 15.000 \\
\hline 4,0 & 29.000 & 18.000 \\
\hline 4,2 & 32.000 & 22.000 \\
\hline 4,4 & 36.000 & 27.000 \\
\hline
\end{tabular}




\begin{tabular}{c|c|c}
\hline \multirow{2}{*}{ Velocidade ultra-sônica $(\mathrm{Km} / \mathrm{s})$} & \multicolumn{2}{|c}{ Módulo de elasticidade $\left(\mathrm{MN} / \mathrm{m}^{2}\right)$} \\
\cline { 2 - 3 } & Dinâmico & Estático \\
\hline 4,6 & 42.000 & 34.000 \\
\hline 4,8 & 49.000 & 43.000 \\
\hline 5,0 & 58.000 & 52.000 \\
\hline
\end{tabular}

Fonte: British Standards Institution (1986)

Conforme os valores de módulo de elasticidade dinâmico apresentados e o maior valor de velocidade de propagação de onda encontrado nos pilares, torna-se possível, por meio de equação contemplada na ABNT NBR 6118 (2014), estimar a resistência à compressão da estrutura para concretos de fck de $20 \mathrm{MPa}$ a $50 \mathrm{MPa}$. De acordo com Shehata (2005) o módulo de elasticidade dinâmico é determinado através de métodos não destrutivos e segundo Lyndon e Balendran (1986) a diferência entre o módulo de elasticidade estático e dinâmico podem variar em valores próximos a 15\%. Para efeito, tem-se a formula abaixo descrita:

$$
E_{C l}=\alpha E \times 5600 \sqrt{f_{c k}}
$$

Onde: $\mathrm{E}_{\mathrm{Cl}}=$ Módulo de elasticidade $(\mathrm{MPa}), \mathrm{F}_{\mathrm{ck}}=$ Resistência característica à compressão do concreto (MPa) e $\alpha \mathrm{E}=$ correspondente ao tipo de agregado que, para granito, adotado na construção, equivale a 1,0 de acordo com ABNT NBR 6118 (2014).

Logo, por meio do ensaio de ultrassom e referências mencionadas, tornou-se possível estimar a resistência do elemento estrutural em 44.33 MPa. Assim, reconhecendo-se sua resistência, além dos materiais empregados, como tipo de cimento e agregados, por meio de consulta aos executores, realizou-se estudo de estimativa de vida útil adotando-se de ensaio acelerado de migração de cloretos, onde se executou a moldagem de protótipo em laboratório com características similares à estrutura existente. Adotou-se o método de migração acelerada de cloretos preconizado pela norma NT BUILD 492 (1999). A partir deste, torna-se possível verificar o coeficiente de difusão de cloretos e efetuar a previsão de vida útil desta estrutura. Identificam-se nas Tabelas 3 e 4 o consumo de materiais e a resistência à compressão para elaboração de protótipo. A relação agua/cimento 0.55 foi adotada por configurar-se a maior relação possível para concreto armado enquadrados em classe de agressividade forte, classificação marinha e com risco grande de deterioração da estrutura, conforme ABNT NBR 6118 (2014).

Tabela 3 - Consumo de materiais por metro cúbico de concreto

\begin{tabular}{c|c|c|c|c|c}
\hline Misturas & Relação a/ag. & $\begin{array}{c}\text { Massa Cimento } \\
\left(\mathrm{Kg} / \mathrm{m}^{3}\right)\end{array}$ & $\begin{array}{c}\text { Massa Areia } \\
\left(\mathrm{Kg} / \mathrm{m}^{3}\right)\end{array}$ & $\begin{array}{c}\text { Massa Brita } \\
\left(\mathrm{Kg} / \mathrm{m}^{3}\right)\end{array}$ & $\begin{array}{c}\text { Teor de aditivo } \\
(1)\end{array}$ \\
\hline REF & 0,55 & 325,45 & 813 & 1118 & 0,975 \\
\hline
\end{tabular}

Tabela 4 - Resistência à compressão axial e abatimento dos corpos de prova aos 28 dias

\begin{tabular}{c|c|c}
\hline Misturas & $\begin{array}{c}\text { Resistência a compressão (MPa) } \\
\text { (ABNT NBR 5739:2007) }\end{array}$ & $\begin{array}{c}\text { Ensaio de abatimento de tronco } \\
\text { de cone (mm) (ABNT NBR NM } \\
67: 1998)\end{array}$ \\
\hline REF & 40,4 & 150 \\
\hline
\end{tabular}

A fim de se obter, a partir de ensaios de migração no estado não estacionário o coeficiente de difusão de cloretos, temse, conforme norma NT BUILD 492 (1999), método que se utiliza de aplicação de diferença de potencial e utilização de indicador colorimétrico (aspersão de $\mathrm{AgNO}_{3}-0,1 \mathrm{M}$ ). Conforme este método, o ensaio tem duração de 24 horas para concretos comuns podendo chegar até 96 horas para concretos de alto desempenho. A duração do ensaio e a voltagem a ser adotada dependerá da leitura inicial de corrente passante na amostra de concreto ao ser aplicada diferença de potencial de $30 \mathrm{~V}$. Neste estudo, em média, a duração do ensaio para cada amostra avaliada foi de 24 horas. O cálculo do coeficiente de difusão aparente de íons cloreto deve ser resolvido a partir da Equação 2. 


$$
D_{n s s m}=\frac{0.0239(273+T) L}{(U-2) t}\left(X_{d}-0.0238 \sqrt{\frac{(273+T) L x_{d}}{U-2}}\right)
$$

Onde $\mathrm{D}_{\text {nssm }}$ é o coeficiente de migração de cloretos em estado não estacionário multiplicado por $10-12\left(\mathrm{~m}^{2} / \mathrm{s}\right) ; \mathrm{U}$ é a diferença de potencial aplicada (V); T é a média de valores da temperatura inicial e final na solução anólita $\left({ }^{\circ} \mathrm{C}\right)$; L é a espessura da amostra $(\mathrm{mm})$; xd é a média da profundidade de penetração de cloretos na amostra (mm), e t é a duração do teste (h). O procedimento de ensaio é representado conforme Figura 5.

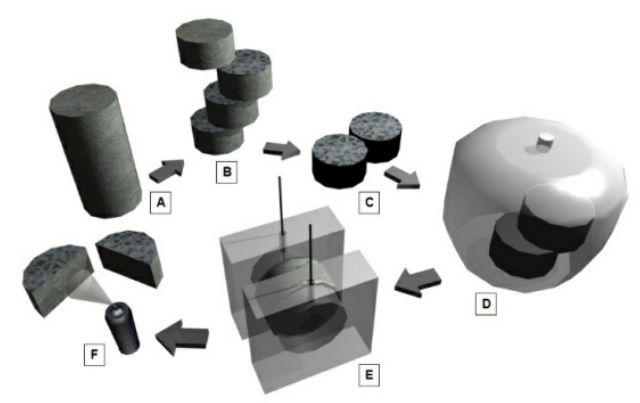

Figura 5: Procedimento adotado no ensaio de migração de cloretos e aspersão de $\mathrm{AgNO}_{3}$ conforme NT BUILD 492 (1999). (a) Corpo de prova, (b) serragem de corpos de prova, (c) selagem das faces laterais, (d) saturação, (e) montagem das células e ( f) aspersão de $\mathrm{AgNO}_{3}$

Por intermédio da obtenção do coeficiente de difusão de íons cloreto, determinado pelo método NT Build 492 (1999), e adotando a segunda Lei da Difusão de Fick da difusão no estado não estacionário, torna-se possível relacionar a profundidade de penetração de cloretos com a vida útil da estrutura (MEDEIROS, 2008). Para efeito, foram utilizadas as Equações 3 e 4 desenvolvidas a partir da Segunda Lei de Fick (HELENE, 2000; MEDEIROS et. al, 2013; Ribeiro et al, 2014 ).

$$
\begin{aligned}
& P C=2(z) \sqrt{D t} \\
& \operatorname{erf}(z)=1-\frac{C_{c l}-C_{0}}{C_{s}-C_{0}}
\end{aligned}
$$

Onde: D é o coeficiente de difusão de cloretos ( $\left.\mathrm{cm}^{2} / \mathrm{ano}\right), \mathrm{t}$ é a vida útil de serviço (anos), erf (z) é a função erro de Gauss, PC (penetração de cloretos) é a profundidade onde a concentração de cloretos alcançou o ponto crítico para despassivação do aço $(\mathrm{cm}), \mathrm{C}_{0}$ é a concentração inicial de cloretos no interior do concreto, $\mathrm{C}_{\mathrm{s}}$ é a concentração na superficie do concreto (\%), $\mathrm{C}_{\mathrm{cl}}$ é a concentração de cloretos ao longo da profundidade (PC) e do tempo (t) (\%).

Para elaboração do gráfico, foram necessárias as definições de alguns parâmetros tal como a fixação de valor de $0,4 \%$ em relação à massa de cimento como valor limite para despassivação das armaduras. Este valor foi adotado em função do contemplado como limite máximo de cloretos em concreto armado orientado em FIB (CEB-FIP) (The International Federation for Structural Concrete) e valor médio entre as normas ABNT NBR 6118:2014, 0,50\%, e a americana ACI318, 0,30\%. Além de configurar valor recomendado por Helene (1993), Browne (1980) e CEB (1992).

Como valor de cloretos na superfície do concreto adotaram-se: 0,9\%, percentual recomendado por Helene (1993) como referencial ou orientativo para concretos com relação água/cimento de 0,48 a 0,68, consumo de cimento de 280 a $400 \mathrm{~kg} / \mathrm{m}^{3}$ e submetidos à névoa salina e $0.6 \%$ percentual sugerido por Guimarães et al. (2007) para edificações distanciadas em até 5.000 metros em relação ao mar. A adoção destes dois percentuais visa preencher uma margem de incerteza em relação a possíveis interferências como: obstáculos ao avanço da névoa salina (árvores e edifícios), pilares abrigados da chuva, dentre outras situações.

$\mathrm{O}$ valor da concentração de cloretos na superfície do concreto a ser adotado, considerando ambientes submetidos à névoa salina, é objeto de discussões. Medeiros (2008) aponta como um valor que possa ser adotado como percentual de cloretos na superfície do concreto de $1,8 \%$. Segundo o autor, este valor situa-se na média de outros percentuais recomendados por Helene (1993), cujo valor é de 0,9\%, e de Guimarães (2000) no qual o valor adotado é de 3,0\% de cloretos na superfície de uma estrutura real com 22 anos de idade e submetida a um ambiente contendo névoa salina. Nunes et al. (2004) avaliaram estruturas de concreto em uso, com idades superiores a 15 anos e diferentes distâncias em relação à água do mar e obtiveram os seguintes valores: $\mathrm{Cs}=3,1 \%$, para distância de zero metros; $\mathrm{Cs}=1,1 \%$, para distância de 160 metros e Cs=0,6\%, para distância de 630 metros. Guimarães et al. (2007) sugerem os seguintes valores de Cs para estimativa de vida útil de projeto: 3,2\%, para zero metros; $1,1 \%$, para 160 metros e $0,6 \%$ para distância entre 
680 e 5.000 metros. Logo, o valor de cloretos na superfície do concreto adotado nesta pesquisa de $0,9 \%$, considerando ambiente submetido à névoa salina, encontra-se condizente com as pesquisas apresentadas.

Baseado nos resultados de penetração de zona carbonatada torna-se possivel também efetuar a estimativa de vida útil da estrutura. O desenvolvimento da carbonatação pode ser previsto através da utilização do coeficiente de carbonatação, seja natural ou seja acelerada, o que indica a profundidade de ingresso $\mathrm{CO}_{2}$ em um determinado tempo. Existem vários modelos matemáticos que relacionam as profundidade com o tempo e/ou outras variáveis. Contudo, o modelo mais utilizado para a determinação do coeficiente é dado pela Equação 5 (ANDRADE, 1992; CASCUDO, 1997).

$$
X=K(t)^{0,5}
$$

Onde: $\mathrm{X}=$ profundidade carbonatada $(\mathrm{mm}) ; \mathrm{K}=$ coeficiente de carbonatação, dependente da difusividade do $\mathrm{CO}_{2}$ (mm.ano -1/2) e $\mathrm{t}=$ tempo de exposição ao $\mathrm{CO}_{2}$ (anos).

Hakkinen (1993), apresenta um modelo para determinar o coefiente de carbonatação (k) obtido por meio da equação:

$$
k=C_{a m b} C_{a r} a\left(f_{c m}\right)^{b}
$$

Onde: $\mathrm{C}_{\mathrm{amb}}=$ coeficiente relativo ao ambiente $(1,0$ - estruturas protegidas da chuva); Car= coeficiente relativo ao teor de ar introduzido no concreto $(\%)(1,0$ - sem ar introduzido); fcm= resistência à compressão média do concreto (MPa) (41); $a, b=$ coeficientes relativos ao tipo de ligante $(a=360 ; b=-1,2-$ cimento Portland $+70 \%$ de escórias $)$

\subsubsection{Procedimento de avaliação de vida útil por meio de ferramenta computacional- Software Life 365}

O software Life 365 foi desenvolvido para estimar a vida útil de estruturas em concreto armado. O período de iniciação (os íons cloreto penetram no cobrimento do concreto por difusão até atingirem as armaduras) é calculado por meio do modelo de difusão apresentada pela $2^{a}$ Lei de Fick. Já o período de propagação (a concentração de cloretos atinge um valor limite admissível definido pela proteção passiva das barras de aço, desencadeando o início do processo de corrosão do aço) é fixado em 20 anos para barras de aço revestidas com époxi e 6 anos para os demais tipos de proteção ou adição. Há a opção de escolher adições aos concretos, como cinza volante, escória de alto forno e sílica ativa.

\subsubsection{Dados de entrada do software Life 365}

Inicialmente, indicaram-se os pilares da edificação como elementos de análise. O cobrimento adotado de referência foi de 4cm, cobrimento mínimo para classe de agressividade III, ambientes marinhos, conforme ABNT NBR 6118:2014. Adotaram-se pilares quadrados com seção transversal de $60 x 60 \mathrm{~cm}$ e 5 metros de altura, conforme situação existente. Em seguida, indica-se a cidade de localização da obra. As cidades contempladas no Life 365 são cidades americanas, logo buscou cidade com similaridades climáticas com a cidade de Cariacica, escolhendo-se a cidade de Miami, estado da Florida. Definiu-se também o grau de exposição ao meio e para efeito adotou-se 1500 metros em relação ao mar, localização da edificação. O software não oferece opção do tipo de cimento, porem apresenta a opção por utilização de adições, escória, cinza volante e sílica ativa. Portanto foi considerado o CPIII com adição de escória por ser o cimento adotado na construção e com maior utilização no estado do Espírito Santo. Para o CPIII adotou-se $70 \%$ de escória concentrações máximas adotadas neste tipo de cimento. A relação água/cimento adotada foi de 0.55 , maior relação permitida para edificações situadas em ambientes marinhos, classe de agressividade III, conforme ABNT NBR 6118 (2014).

\subsubsection{Procedimento de avaliação de vida útil por meio de ferramenta computacional- Software Carambola}

O software possibilita a previsão do período de iniciação da corrosão por carbonatação. Para efeito, pode-se optar por cálculos deterministas e probabilistas. De acordo com Carmona (2005), o cálculo determinista é realizado encontrandose o valor do período de iniciação "t" necessário para que a profundidade de carbonatação se iguale ao cobrimento de armaduras fornecido. O cálculo probabilista se supõe distribuições normais para a carbonatação e para os cobrimentos.

\subsubsection{Dados de entrada do software Carambola}

Os valores de entrada para o cálculo pelo método determinista foram: cobrimento de $4 \mathrm{~cm}, \mathrm{Fck}$ de $41.33 \mathrm{MPa}, \mathrm{CO}_{2}$ de 0.1\% (Helene, 1993) e cimento CPIII. Para o método probabilista os dados de entrada foram também o 'fck', 'tipo de 
cimento' e 'cobrimento'. A concentração de $\mathrm{CO}_{2}$ no ambiente adotado foi também de 0,1\%, segundo Helene (1993). Adotou-se CV para carbonatação igual a $25 \%$ e CV do cobrimento igual a 25\%, de acordo com Helene (1997). Para a probabilidade de despassivação foi adotado o valor de $50 \%$.

\section{RESULTADOS E DISCUSSÕES}

Após a realização dos ensaios, puderam ser identificados os resultados a fim de verificar a integridade da estrutura. A Tabela 5 identifica os resultados de velocidade de propagação de onda nos pilares ensaiados

Tabela 5 - Resultados de ensaio de velocidade de propagação de onda ultrassônica

\begin{tabular}{c|c|c}
\hline Local de detecção & $\begin{array}{c}\text { Velocidade longitudinal da onda } \\
\text { em (Km/s) }\end{array}$ & Qualidade do concreto \\
\hline Pilar 01 & 4,2 & Muito boa \\
\hline Pilar 02 & 4,2 & Muito boa \\
\hline Pilar 03 & 4,4 & Muito boa \\
\hline Pilar 04 & 4,4 & Muito boa \\
\hline Pilar 05 & 4,3 & Muito boa \\
\hline
\end{tabular}

A partir dos resultados, percebe-se a homogeneidade dos concretos dos pilares e a sua qualidade, classificados como de qualidade muito boa (RIBEIRO et. al, 2014). Visando ratificar que os pilares dos concretos apresentam estrutura uniforme foi realizado ensaio de esclerometria nos pilares seguindo as diretrizes da NBR 7584 (2012). Adotou-se o esclerometro analógico conhecido como martelo de Shimit e efetuou-se a demarcação do quadro de $20 \times 20 \mathrm{~cm}$, dividindo em uma matriz de $4 \times 4$, com $5 \times 5 \mathrm{~cm}$ de cada lado. Foram analisados os 3 pilares centrais em duas alturas em relação ao piso: $170 \mathrm{~cm}$ (altura A) e 50cm (altura B). Realizou-se a média aritimética dos resultado obtidos (MI), depois desprezou-se os valores com índices esclerométricos que estejam distantes em mais de 10\% do valor médio e calculada uma nova média aritimética (MII). O índice de escleromtria corrigido foi calculado a partir da Equação 7, fornecida pelo fabricante:

$$
R=\frac{0,19 M I I^{2,0535}}{10}
$$

Por meio dos resultados de esclerometria (Tabela 6), constatou-se a uniformidade entre os pilares apresentando baixo coeficiente de variação nos resultados de resistência à compressão (MPA). Notou-se uniformidade ao longo da altura de um mesmo pilar não evidenciando falhas de execução oriundas do processo de lançamento do concreto (segregação).

Tabela 6 - Resultados do ensaio de índice de esclerometria

\begin{tabular}{|c|c|c|c|c|c|c|c|}
\hline Local do Ensaio & $\begin{array}{l}\text { Índice } \\
\text { Esclero } \\
\text { métrico } \\
(\mathrm{M} \mathrm{I})\end{array}$ & $\begin{array}{l}\text { Índice Pós } \\
\text { Média (M } \\
\text { II) }\end{array}$ & $\begin{array}{c}\text { Índice } \\
\text { Escleromé } \\
\text { trico } \\
\text { Corrigido } \\
\text { (MPA) }\end{array}$ & $\begin{array}{c}\text { Desvio } \\
\text { Padrão MI }\end{array}$ & $\begin{array}{c}\text { Coeficiente } \\
\text { de Variação } \\
\text { MI }\end{array}$ & $\begin{array}{l}\text { Média } \\
\text { (MPA) }\end{array}$ & $\begin{array}{l}\text { Coeficient } \\
\text { e de } \\
\text { Variação } \\
\text { (MPA) }\end{array}$ \\
\hline Pilar 1 - Altura A & 42,06 & 43,46 & 43,91 & 3,45 & $8,21 \%$ & \multirow{6}{*}{45,70} & \multirow{6}{*}{$3,68 \%$} \\
\hline Pilar 1 - Altura B & 42,50 & 43,50 & 43,99 & 3,39 & $7,97 \%$ & & \\
\hline Pilar 2 - Altura A & 44,38 & 44,00 & 45,04 & 2,06 & $4,65 \%$ & & \\
\hline Pilar 2 - Altura B & 43,94 & 44,47 & 46,02 & 2,49 & $5,67 \%$ & & \\
\hline Pilar 3 - Altura A & 46,25 & 45,33 & 47,89 & 3,79 & $8,19 \%$ & & \\
\hline Pilar 3 - Altura B & 44,81 & 45,08 & 47,35 & 4,51 & $10,05 \%$ & & \\
\hline
\end{tabular}

Com relação à identificação de cloretos livres (aspersão de $\mathrm{AgNO}_{3}$ ), constatou-se camada contaminada de $20 \mathrm{~mm}$. $\mathrm{O}$ cobrimento adotado foi de $40 \mathrm{~mm}$, logo a frente de cloretos retratada pelo indicador colorimétrico alcançou $50 \%$ do percurso em relação à armadura. Após a aspersão de fenolftaleína (frente de $\mathrm{CO}_{2}$ ), identificou-se espessura carbonatada de $22 \mathrm{~mm}$, configurando-se como aquela onde não houve coloração vermelha escura, PH ácido. A partir dos modelos apresentados nas Equações 3 e 4 foi possível construir o gráfico que relaciona a profundidade de penetração de cloretos com a estimativa da Vida Útil de Projeto (VUP) para os concretos analisados (Figura 6). 


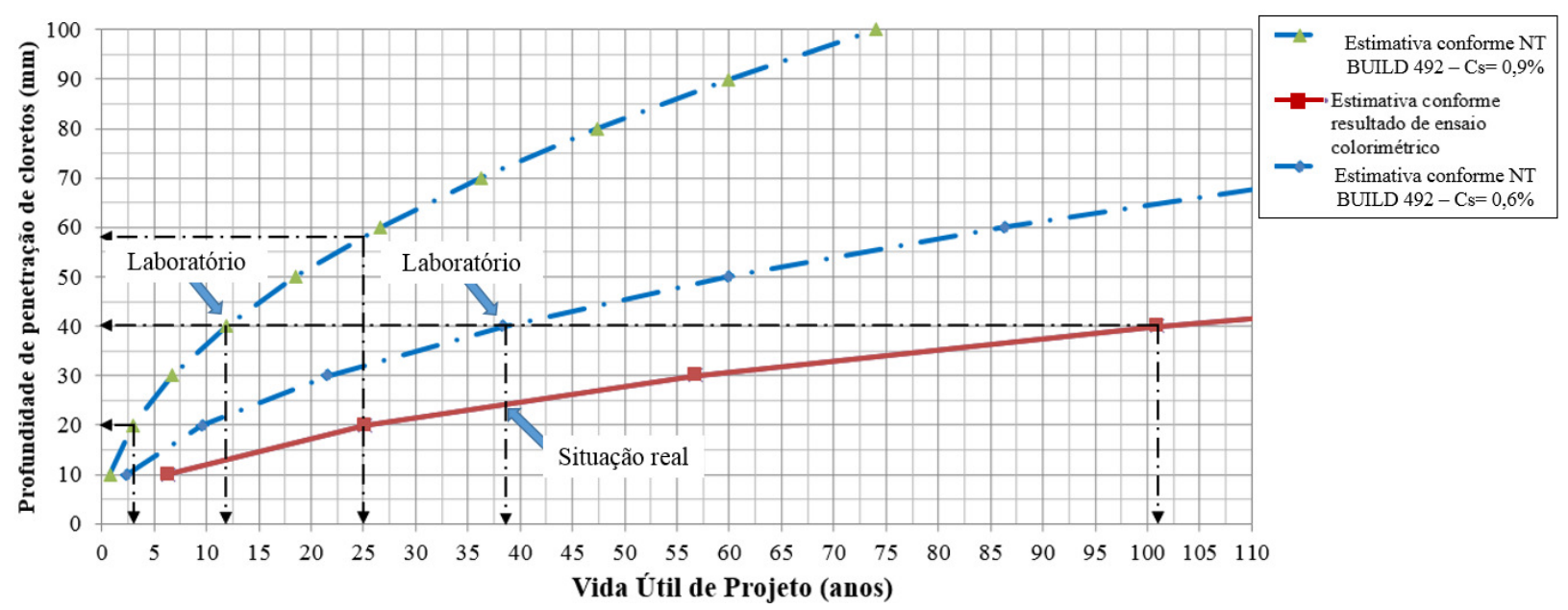

Figura 6: Estimativa de vida útil em relação à exposição à névoa salina

Conforme a estimativa de Vida Útil de Projeto (VUP) realizada referente aos concretos produzidos em laboratório, o percentual de cloretos atinge a armadura com o cobrimento de $40 \mathrm{~mm}$ em torno de 12 anos para concentração superficial de cloretos de $0,9 \%$ e de em torno de 38 anos para a concentração de cloretos de $0,6 \%$. Entretanto, observou-se que na estrutura real (idade de 25 anos) a frente de cloretos alcançou apenas $20 \mathrm{~mm}$ do cobrimento (conforme constado no ensaio de aspersão de nitrato de prata), nesta perspectiva alcançará a armadura em torno de 100 anos, representando o dobro do tempo solicitado pela NBR 15575 e EN 206-1 (2007). A perspectiva conforme a utilização do método acelerado (NT BUILD 492), necessitaria de um cobrimento de $60 \mathrm{~mm}$ (para $\mathrm{Cs}=0,9 \%$ ) e $30 \mathrm{~mm}$ (para $\mathrm{Cs}=0,6 \%$ ) para atingir os mesmos 25 anos, estado atual da edificação. Nota-se, que a utilização de métodos acelerados de migração de cloretos para a obtenção de estimativas de vida útil deve ser realizada com cautela, tendo em vista que o processo de ingresso de cloretos em concretos depende de vários fatores, tais como presença de umidade (eletrólito), efeito da temperatura, direção dos ventos, dentre outras que precisam ser consideradas. Por meio das equações 5 e 6 , torna-se possível construir o gráfico da estimativa do avanço de carbonatação durante a vida útil da edificação (Fig. 7).

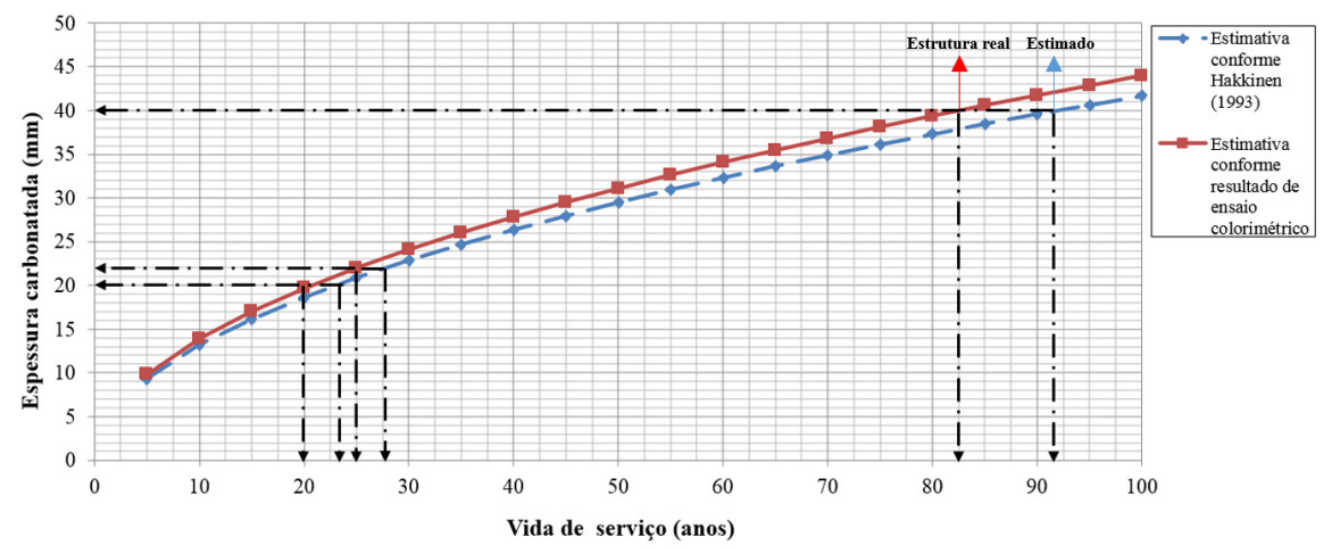

Figura 7. Estimativa de vida útil em relação à frente de carbonatação

Verifica-se que com relação à estimativa de Vida Útil de Projeto (VUP) a partir do ingresso de $\mathrm{CO}_{2}$ e processo de carbonatação do concreto, conforme Hakkinen (1993), com o cobrimento de 40mm haveria uma vida útil em torno de 82 anos e a estimativa conforme verificação in-loco, por meio do ensaio de Fenolftaleína, e perspectiva de evolução conforme Equação 5, em pouco mais de 90 anos, diferença em torno de 8\% (Figura 7). O ensaio de fenolftaleína acusou uma carbonatação de $22 \mathrm{~mm}$ em 25 anos enquanto que a estimativa segundo Hakkinen (2013) acusou esta penetração em cerca de 27.5 anos, logo valor muito próximo ao estimado. Nota-se que em ambas as análises a vida útil mínima recomendada para a edificação conforme NBR 15575 de 50 anos é alcançada com uma frente de carbonatação de em torno de 30mm, não alcançando o cobrimento de 40mm. Por meio dos software 365 Life e Carambola, tornou-se também possível obter resultados de vida útil sob a ótica da exposição a cloretos e à incidência de $\mathrm{CO}_{2}$, respectivamente. Os resultados são confrontados com aqueles obtidos pelos outros métodos apresentados (Tabelas 7 e 8 e Figura 8) 
Tabela 7- Estimativas de vida útil

\begin{tabular}{|c|c|c|c|c|c|}
\hline Agente agressivo & Metodologia & $\begin{array}{l}\text { Cobrimento } \\
\text { do concreto } \\
(\mathrm{mm})\end{array}$ & $\begin{array}{l}\text { Estimativa } \\
\text { de vida útil } \\
\text { (anos) }\end{array}$ & $\begin{array}{l}\text { Cobrimento } \\
\text { do concreto } \\
(\mathrm{mm})\end{array}$ & $\begin{array}{l}\text { Estimativa de } \\
\text { vida útil (anos) }\end{array}$ \\
\hline \multirow{3}{*}{ Névoa salina } & $\begin{array}{l}\text { Estimativa conforme NT Build } \\
492 \text { - Estimado }(\mathrm{Cs}=0.9 \%)\end{array}$ & 20 & 3 & 40 & 12 \\
\hline & Software 365 Life - Estimado & 20 & 3,5 & 40 & 12,5 \\
\hline & $\begin{array}{l}\text { Estimativa por meio de } \\
\text { indicador colorimétrico } \\
\left(\mathrm{AgNO}_{3}\right) \text { - Medido }\end{array}$ & 20 & 25 & 40 & $>100$ \\
\hline \multirow{3}{*}{$\mathrm{CO}_{2}$} & $\begin{array}{c}\text { Estimativa conforme Hakkinen } \\
\text { (2013) - Estimado }\end{array}$ & 20 & $>22$ & 40 & 90 \\
\hline & Software Carambola - Estimado & 20 & 62 & 40 & $>248$ \\
\hline & $\begin{array}{c}\text { Estimativa por meio de } \\
\text { indicador colorimétrico (Nitrato } \\
\text { de prata) - Medido }\end{array}$ & 20 & 20 & 40 & $>82$ \\
\hline
\end{tabular}

Tabela 8 - Vida útil mínima para sistemas e tipos de estruturas conforme diferentes normas

\begin{tabular}{c|c|c|c|c|c}
\hline \multicolumn{2}{c|}{$\begin{array}{c}\text { NBR 15575 (VUP, anos) - } \\
\text { Sistemas }\end{array}$} & \multicolumn{2}{c|}{$\begin{array}{c}\text { BS 7543 (1992) (VUP, anos) - } \\
\text { Tipos de estruturas }\end{array}$} & \multicolumn{2}{c}{$\begin{array}{c}\text { EM 206-1 (2007) (VUP, anos) - Tipos de } \\
\text { estruturas }\end{array}$} \\
\hline Estrutura & $\geq 50$ & $\begin{array}{c}\text { Obras de arte e edifícios } \\
\text { públicos novos }\end{array}$ & $\geq 120$ & $\begin{array}{c}\text { Edifícios monumentais, pontes e } \\
\text { outras estruturas de engenharia civil }\end{array}$ & $\geq 100$ \\
\hline Vedação vertical externa & $\geq 40$ & $\begin{array}{c}\text { Edifícios novos e } \\
\text { reformas de edifícios }\end{array}$ & $\geq 60$ & Edifícios e outras estruturas comuns & $\geq 50$ \\
\hline Vedação vertical interna & $\geq 20$ & $\begin{array}{c}\text { Edifícios industriais e } \\
\text { reformas }\end{array}$ & $\geq 30$ & $\begin{array}{c}\text { Estruturas para agricultura e } \\
\text { semelhantes }\end{array}$ & 15 a 30 \\
\hline Cobertura & $\geq 20$ & Substituíveis & $\geq 10$ & $\begin{array}{c}\text { Partes estruturais substituíveis (Ex.: } \\
\text { apoios) }\end{array}$ & 10 a 25 \\
\hline Hidrossanitário & $\geq 20$ & Temporárias & $\geq 10$ & Temporárias & $\geq 10$ \\
\hline
\end{tabular}

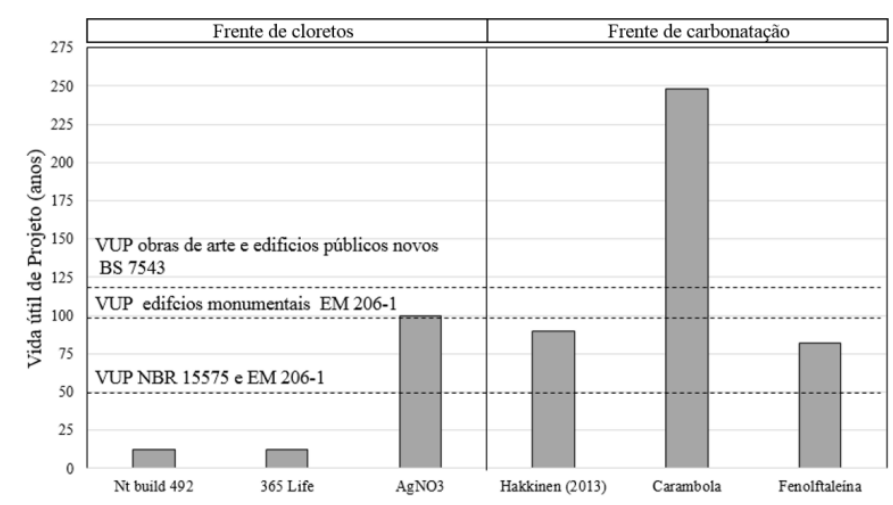

Figura 8. Estimativas de Vida Útil de Projeto por diferentes métodos

Nota-se que a perspectiva de avanço de cloretos, tanto por meio de estimativa por meio de utilização de protótipo e avaliação conforme NT BUILD 492, quanto pelo uso do software 365 Life, ferramentas comuns de auxílio na previsão de vida útil em estruturas, apresentaram correspondênica entre os resultados, porém constataram uma vida útil significativamente inferior à vida útil constatada por meio da avaliação por indicador colorimétrico. Sendo assim, constata-se que a edificação em seu estágio atual tenderá a atender a vida útil mínima de projeto prevista pela NBR 15575 e EN 206-1 (2007) e ainda o previsto em BS 7543 (1992) para edifícios públicos novos. Isto pode ter ocorrido em função da orientação da edificação (incidência de ventos dominantes) e abrigo da chuva. A presença da umidade e chuva dirigida é um fator relevante para intensificar o ingresso de íons cloretos na estrutura (MEDEIROS, 2008). Recomenda-se que quando for revestir os elementos estruturais externos, seja feita uma avaliação por aspersão de $\mathrm{AgNO}_{3}$, a fim de avaliar o quanto a frente de cloretos avançou. Seu resultado poderá ser lançado no gráfico apresentado 
na Figura 9, porém sabe-se que com a adoção de revestimentos ou outros sistema de proteção superficial (proteção ao cobrimento da armadura) a vida útil tenderá a se potencializar.Verificou-se correspondência entre a estimativa de de vida útil por meio do ingresso de $\mathrm{CO}_{2}$ entre o concebido por Hakkinen (2013) e o aferido in-loco por meio do ensaio de fenolftaleína. A estimativa por meio de ferramenta computacional não apresentou correspondência com os outros resultados. Nota-se que a carbonatação do concreto alcançou apenas cerca de $50 \%$ do percurso em relação à armadura e que o alcance à armadura ocorrerá em torno de 80 anos. Novamente a estimativa de vida útil atendeu aos requisitos normativos com relevância.

\section{CONCLUSÕES}

1. Constatou-se, a partir dos ensaios executados, a percepção obtida na inspeção visual, que a edificação manteve sua integridade apesar de não terem sido promovidos mecanismos de conservação ao longo de sua vida de serviço.

2. Identificou-se que o avanço da frente de cloretos atingiu em 25 anos apenas $50 \%$ do cobrimento adotado. Nesta perspectiva, a estimativa de 50 anos de vida útil para a edificação seria atendida com um cobrimento em torno de $30 \mathrm{~mm}$. Com o cobrimento especificado de $40 \mathrm{~mm}$ a armadura só seria atingida em 100 anos, atendendo a vida útil mínima requerida até dos mais exigentes normativos internacionais.

3. A estimativa de Vida Útil de Projeto (VUP) realizada, de acordo com Hakkinen (1993), apresentou correspondência com o estágio atual de frente de carbonatação. A frente de cloretos de acordo com a NT BUILT 492, adotando-se concentração superficial de cloretos de 0,9\% conforme Helene (1993), apresentou menor expectativa de vida em relação ao estágio atual (verificada por meio de avaliação por indicador colorimétrico). Isso pode ter ocorrido pela diferença de concentração superficial de cloretos adotada na estimativa e no caso real em função de regime dos ventos e incidência de chuva que facilitaria o sistema de transporte de cloretos.

4. Indicou-se que as estimativas de vida útil da iniciação da corrosão das armaduras por cloretos tendem a ser mais rigorosas que o caso real em até $800 \%$ e que o avanço da frente de cloretos pode variar significantemente em função de fatores diversos. A análise pela frente de carbonatação tendeu a representar menor influencia entre a VUP estimada e o seu estágio VUP atual.

5. A estimativa de vida útil por ferramentas computacionais da iniciação da corrosão das armaduras por carbonatação e por cloretos não produziram equivalência com o estado atual da edificação.

6. Baseado na análise comparativa dos resultados de vida útil, a utilização de indicadores colorimétricos para previsão de vida útil tende a ter maior confiabilidade que as previsões adotando-se métodos probabilistas, estimativas por métodos acelerados ou ferramentas computacionais. Para uma análise posterior à execução da obra, a análise por indicadores colorimétricos torna-se uma interessante opção. Caso haja a possibilidade de investigação em construções próximas ou haja viabilidade de tempo para a adoção de protótipo experimental para a investigação em situações reais este recurso também é de relevante valia.

\section{REFERÊNCIAS}

ACI Committee 201 “Guide to Durable Concrete." Report No. ACI 201-2R-92, American Concrete Institute. Farmington Hills, MI, 1992.

AMERICAN CONCRETE INSTITUTE. ACI-228-1R-89: In Place Methods for Determination of Strenght of Concrete, Detroit, 26pp, 1989.

ANDRADE, J. J. (1997) Dissertação de Mestrado. Durabilidade das estruturas de concreto armado: Análises das Manifestações Patológicas nas Estruturas no Estado de Pernambuco. Programa de Pós-Graduação em Engenharia Civil, UFRGS.148p.

ANDRADE, C. Manual para diagnóstico de obras deterioradas por corrosão de armaduras. São Paulo: PINI, 1992. 104p.

ASSOCIACAO BRASILEIRA DE NORMAS TECNICAS. NBR 6118 NB1: projeto de estruturas de concreto procedimento. Rio de Janeiro, 1968, rev. Abril, 2014.

ASSOCIACAO BRASILEIRA DE NORMAS TECNICAS. NBR 8802. Concreto endurecido - Determinação da velocidade de propagação de onda ultrassônica. 2013 
ASSOCIACAO BRASILEIRA DE NORMAS TECNICAS. NBR NM 58: Concreto endurecido - Determinação da velocidade de propagação de onda ultra sônica. 1996

ASSOCIACAO BRASILEIRA DE NORMAS TECNICAS. NBR 7584:2012: Concreto endurecido - Avaliação da dureza superficial pelo esclerômetro de reflexão - Método de ensaio. Rio de Janeiro, 2012.

ASSOCIACAO BRASILEIRA DE NORMAS TECNICAS. NBR 15575-1:2008: Edifícios habitacionais de até cinco pavimentos - Desempenho - Parte 1: Requisitos gerais. Rio de Janeiro, 2008. 52p.

BRITISH STANDARD INSTITUTION, BS EN 12504: Part 4. Determination of ultrasonic pulse velocity. 2004.

BRITISH STANDARD INSTITUTION, BS 1881: Part 204. Recommendations on the use of electromagnetic covermeters. 1988.

BRITISH STANDARD INSTITUTION, BS 1881-Part 203. Recommendations for measurement of the velocity of ultrasonic pulses in concrete. London, 1986.20p.

CASCUDO, O. (1997), Controle da corrosão de armaduras em concreto.Goiânia: UGF.

CARMONA, T. G. Modelos de previsão da despassivação das armaduras em estruturas de concreto sujeitas à carbonatação. 2005. 103 f. Dissertação (Mestrado) - Curso de Engenharia Civil, Escola Politécnica, Universidade de São Paulo, São Paulo, 2005.

GLEIZE, P. J. P., CYR, M., ESCADEILLAS, G. Effects of Metakaolin on Autogenous Skrinkage of Cements Pastes. Cement \& Concrete Research, Vol. 29, p. 80-87. 2007.

GUIMARÃES, A. T. da C. Vida útil de estruturas de concreto armado em ambientes marítimos. 2000.241 p. Tese (Doutorado) - Escola Politécnica, Universidade de São Paulo, 2000.

GUimarÃeS, A.T.C., CASTRO, P., NUNES, J.L.O., "Teor de Cloretos Próximos a Superfície do Concreto em Ambientes Marítimos", In: Anais do 49 Congresso Brasileiro do Concreto, Bento Gonçalves, Rio Grande do Sul, Brasil, 2007.

HAKKINEN, T. (1993) Influence of high slag content on the basic mechanical properties and carbonation of concrete,Technical Research Center of Finland, Espoo Publication 141, 98pp., v. 89, n.1, pp. 49-53, 1993.

HELENE, P. (2001) Introdução da vida útil no projeto das estruturas de concreto. Workshop sobre durabilidade das construções. Novembro. São José dos Campos.

HELENE, P. (1993), “Contribuição ao estudo da corrosão em armaduras de concreto armado" Tese de Livre Docência, Escola Politécnica, Universidade de São Paulo, São Paulo.

HElEne, P. A Nova ABNT NBR 6118 e a Vida Útil das Estruturas de Concreto. In: Seminário de Patologia das Construções, 2, 2004, Porto Alegre. Proceedings... Porto Alegre: Novos Materiais e Tecnologias Emergentes, LEME, UFRGS, 2004. v. 1. p. 1-30

HELENE, P. Protección y Mantenimiento de las Superfícies de Hormigón. In: CASANOVAS, X. Manual de Diagnosis e Intervención en Estructuras de Hormigón Armado. Espanha: Col-legi d'Aparelladors i Arquitectes Tècnics de Barcelona, Capitulo 12, p. 115-126.2000.

HELENE, P. Vida útil das estruturas de concreto In: IV CONGRESSO IBEROAMERICANO DE PATOLOGIA DAS CONSTRUÇÕES. Anais...Porto Alegre. RS. 1997.

ISAIA, G. C. (2001) Durabilidade do concreto ou das estruturas de concreto reflexões sobre o tema. Workshop sobre durabilidade das construções. Novembro. São José dos Campos. 
KAMALI, M.; GHAHREMANINEZHAD, A. Effect of glass powders on the mechanical and durability properties of cementitious materials. Const. and Building Materials, v.98, p. 407-416, 2015.

LYNDON, F.D.; BALANDRAN, R.V. Some observations on elastic properties of plain concrete. Cement and Concrete Research, 16, n³, p. 314-324, 1986.

LUPING, T. Nilsson, L. Rapid determination of the chloride diffusivity in concrete by applying an electrical field. ACI Materials Journal, v. 89, n.1, pp. 49-53, 1992.

MEDEIROS, Marcelo Henrique Farias de; GOBBI, Andressa; GROENWOLD, J. A.; HELENE, Paulo. Previsão da vida útil de concreto armado de alta resistência com adição de metacaulim e sílica ativa em ambientes marinhos. Rem: Rev. Esc. Minas [online]. 2013, vol.66, n.1, pp.59-65.

MEDEIROS, M.H.F. Contribuição ao estudo da durabilidade de concretos com proteção superficial frente à ação de íons cloretos. São Paulo: Universidade de São Paulo, Brasil, 2008. (Tese de Doutorado).

NEVILlE, A. M. Propriedades do concreto. $2^{\text {a }}$ ed. São Paulo: Pini, 1997.

MEDEIROS, A. Aplicação do ultrassom na estimativa da profundidade de fendas superficiais e na avaliação da eficácia de injeções em elementos de concreto armado. Dissertação de Mestrado em Engenharia Civil da Universidade Federal de Santa Catarina. Florianópolis, 2007.

NAIK, T. R.; MALhOTRA, V. M.; POPOVICS, J. S., The Ultrasonic Pulse Velocity Method, CRC handbook on nondestructive testing of concrete, Tarun R. Naik and V M Malhotra eds, CRC Press, pp 169-189, 2004.

NORDTEST METHOD, Concrete, mortar and cement-based repair materials: chloride migration coefficient from non-steady-state migration experiments: NT BUILD 492, Oslo, Norway 1999.

NUNES, J. L. 0.; Guimarães, A. T. C.; Silveira, B. P.; Guimarães, D. L. C.; Oliveira, M. T.; Rodrigues, N. D. Intensidade de ataque de cloretos: considerações sobre a distância do concreto em relação à água do mar. In: Seminário e Workshop em Engenharia Oceânica - SEMENGO. Rio Grande, FURG, 2004.

PAULETTI, C. (2009) Estimativa da carbonatação natural de materiais cimentícios a partir de ensaios acelerados e de modelos de predição. Tese (Doutorado em Engenharia Civil) - Escola de Engenharia Civil, Universidade Federal do Rio Grande do Sul, Porto Alegre, 2009.

RIBEIRO, D. V. (2014), Corrosão em Estruturas de Concreto Armado: Teoria, Controle e Métodos de Análise. São Paulo: Elsevier.

SANTOS, J. M. M. N. Avaliação da integridade estrutural de pontes de betão: o caso da Ponte Nossa Senhora da Guia. Dissertação de Mestrado, FEUP, Porto: 2008.

SHEHATA, L.D. Deformações instantâneas de concreto. In: ISAIA, G.C. (Ed.). Concreto: ensino, pesquisa e realizações. São Paulo: IBRACON, 2005.

SOUSA, V. C. M. (1998), Patologia, Recuperação e Reforço de Estruturas de Concreto. São Paulo: PINI,

THOMAS, M. D. A.; BAMFORTH, P. B. Modelling chloride diffusion in concrete. Effect of fly ash and slag. Cement and Concrete Research, v. 29, pp. 487-495, 1999.

WHITING, D. Rapid determination of the chloride permeability of concrete. Final Report No. FHWA/RD-81/119, Federal Highway Administration, August 1981, NTIS No. 82140724 